\title{
The Effects of $\beta$-Glucan on Pig Growth and Immunity
}

\author{
Vaclav Vetvicka ${ }^{1, *}$, Luca Vannucci ${ }^{2}$ and Petr Sima ${ }^{2}$ \\ ${ }^{1}$ University of Louisville, Department of Pathology, Louisville, KY 40202, USA \\ ${ }^{2}$ Institute of Microbiology, Department of Immunology, Prague, Czech Republic
}

\begin{abstract}
With increasing amounts of data showing significant immunostimulating effects of glucan, it is not surprising that attention is also focused on commercially farmed animals. Despite marked progress, development of more efficient uses of glucan in pig farming still needs substantial additional research.
\end{abstract}

Keywords: Glucan, Health, Immunity, Immunostimulation, Nutrition, Pig.

\section{INTRODUCTION}

Carbohydrate structures generally play critical roles in potentiation of immunity, and they are predicted to provide a wide area for discovery of new kinds of safe and welltolerable immune adjuvants. Among numerous carbohydrates, the most promising are the glucans ( $\beta$-D-glucans, hereafter referred to as "glucans"). These compounds represent basic structural units of cell walls of higher plant, algae, fungi, yeast, and several other bacterial species. They are composed of repeating D-glucose units joined together by glycosidic bonds in various conformations. Glucans exert adjuvant activities through their capability to bind to specific surface carbohydrate receptors, such as CR-3 and Dectin-1, expressed on the monocyte-macrophage cell lineage and other antigen-presenting immunocompetent cells, $i$. $e$. dendritic cells. The attachment of glucan molecules to these receptors results in the activation of a cascade of pathways that subsequently increase the production of proinflammatory cytokines and chemokines inducing antigen presentation and cellular co-stimulation, which leads to enhancing of both humoral and cellular immunity. On the other hand, the main aim in search of new safe adjuvants with no exerting damaging side effects such as excessive inflammation is to utilize natural compounds such as glucans, or to construct new substances that give rise to cell activation by other pathways than through NF- $\mathrm{kB}$. Many studies conducted in recent years suggest that glucans represent promising and the most convenient candidates for such safe immunostimulants.

The innate immune system is fairly well conserved among vertebrates due to its roots in evolutionary history. It is estimated that the innate system goes as far back as early metazoan [1]. This retention through time of the innate system explains the effects of glucans throughout the animal species where no animal resistant to glucans effects was found.

*Address correspondence to this author at the University of Louisville, Department of Pathology, 511 S. Floyd, Louisville, KY 40202, USA; Tel: 502-852-1612; Fax 502-852-1177;

E-mail: Vaclav.vetvicka@ louisville.edu

\section{WHY GLUCAN IN PIGS?}

The ban on growth and immunity promoting antibiotics in animal feed in Denmark in 1995 and in the European Union in 1997 and on further remaining antibiotics in 1999, caused increased economic losses due to increased morbidity and mortality of breeding animals. Consequently, it increased the need for exploration of new options on how to utilize safe compounds different from antibiotics. This resulted in acceleration and an intensive search for substances which could improve the growth and health of food animals such as pigs [2]. It was repeatedly shown that the most convenient was the molecules bearing polysaccharide moieties, particularly the glucans, which exerted desired properties.

It was previously proven in the studies that in mice fed orally by glucan obtained from the culture filtrate of the fungus Sclerotinia sclerotiorum, this supplementation enhanced the acid phosphatase, phagocytic, and candidacidal activities, as well as hydrogen peroxide $\left(\mathrm{H}_{2} \mathrm{O}_{2}\right)$ and interleukin-1 (IL-1) production of peritoneal macrophages [3].

Also since the 1990s, it has been reported that glucans stimulated respiratory burst activity enhanced the nonspecific defense mechanisms that induced resistance against a wide range of bacteria in any fish species studied [4-9, for review on the regulation of fish immunity by glucans see $10]$.

Currently, most studies referring the immunomodulating properties of glucans have been performed in mice, rats, and fish. Unfortunately, little is known about their action in commercially important mammals such as pigs or cattle. Based on data obtained in other animal species, it could be expected that glucans influence pig immune parameters, especially the non-specific branch of immunity in a similar way as in other animals. Some authors applied glucans derived from various sources in weaning and finishing pigs and proved their beneficial effects on both the growth and the immunity [11-14]. On the other hand, Hiss and Sauerwein [15] found no substantial effects of dietary glucans on the pig immunity; as glucan-treated pigs had 
immune parameters tested that were similar to the controls and only a marginal benefit on growth performance. However, these negative results might be caused by the quality of relatively unknown glucans used in this study. In addition, no further information other than the Saccharomyces cerevisiae origin was provided. Low effects of glucan supplementation were also found by the Amornlertviman's group. They found little effects on antibody titers to various infections, but positive changes in some hematology data, making the whole study rather inconclusive [16].

The weaning period in pigs is a critical phase for functional differentiation of immunity and growth. Newlyweaned piglets met with plenty of challenges of which infections were the most important. A more rapid rise of immunocompetence and steady growth in piglets is possible to achieve by dietary interventions [17].

\section{GLUCANS IN PIG GROWTH}

A mechanism through which glucan supplementation of pig food formula improves pig growth performance is unknown. Glucans originally used as broad spectrum immunopotentiators can also improve gastrointestinal (GI) health milieu by increasing mucosal barrier functions and contributing to the increase of animal growth. Within GI, the nutrients are digested and through intestinal mucosa absorbed into the body. Glucans may have substantial influence on the composition of intestinal microbiota, which not only helps digestion but directly and indirectly may support immune activities of the gut associated lymphoid tissue (GALT) representing the largest immune organ in mammals. Unfortunately, there are little studies on the relationships between glucans and gut microbiota. One of the few exceptions is the study of Ewaschuk et al. [18], in which the authors investigated the effects of glucan supplementation on selected immune and intestinal parameters in weaning periods in pigs. Addition of glucan to the food resulted in increased mannitol permeability and conductance to the ileus, but the rest of the morphological parameters were not changed. Supplementation particularly influenced expression of lymphocyte phenotypes and lymphoid cell proliferation in response to stimulation, and ex vivo of enterotoxigenic Escherichia coli adhesion to enterocytes. The proportion of CD4 $\mathrm{T}$ cell subpopulations in mesenteric lymph nodes, Peyer's patches and CD8 T cells in peripheral blood was greater in pigs fed with glucan. It was concluded that a greater nutritional intake of glucan resulted in a greater increase of peripheral blood leukocytes and specifically increased the counts of naïve $T$ cells.

The increased mannitol permeability caused by glucan was further studied by Virschevskaya, who found no expected increase of activated $\mathrm{T}$ lymphocytes in mesenteric lymph nodes or Peyer's patches, suggesting some nonimmunologic mechanisms [19].

It is also known that the indigestible polysaccharides stimulate activity of the mucosa and tight junctions or both in the pig intestine [20]. The influence of glucans on the alteration of gut microbiome composition, its metabolic activity and subsequently the gut wall permeability could consequently postpone immune activity of GALT. Immune effects after glucan administration are absent in animals kept in gnotobiologic conditions [21].

A very important component of the porcine gut microflora represents the methanogens. Methanogens belong to the Archea, a distinct domain of bacteria that produces methane in anoxic conditions of hindgut of monogastric animals, where they reduce carbon dioxide and formate and acetate to methane. They play a critical role with regard to efficiency of microbial participation in digestion within GI [22]. Luo et al. [23] In their molecular study investigating the phylogenetic diversity of these microorganisms from porcine colonic digesta for the first time, it confirmed that the addition of glucans significantly increased methanogens diversity. This action may improve the microbiota fermentation activities and positively influence postnatal development of immunity and growth performance.

\section{GLUCANS IN PIG IMMUNITY}

It was shown by Li et al. [24] that diets supplemented with glucan partially down-regulated the synthesis of proinflammatory cytokines TNF- $\alpha$ and IL- 6 modulating immunity but also regulating metabolism of nutrients with damaging effects on growth performance [25]. In addition, glucan up-regulated anti-inflammatory cytokine IL-10 inhibiting $\mathrm{T}$ cell proliferation and functional differentiation including secretion of Th1 and Th2 cytokines, which simultaneously exhibits signal transduction pathway of NF$\kappa \mathrm{B}$ [26]. Li et al. [24] hypothesize that supplementation of pig diet by glucan may suppress cellular immunity, which reflects in increased growth performance [18].

Additional studies have found that the addition of glucans to pig feed increased weight [11,27], reduced peak net glucose flux [28], decreased Th-related cytokine production [29] and protected against infection [30]. In a study focused on evaluation of the effects of glucans on immune parameters in pigs with experimental ascariosis, glucan combined with pig immunoglobulin and zinc was found to significantly elevate the levels of both peripheral blood $\mathrm{T}$ and $\mathrm{B}$ cells and stimulate the phagocytic activity of white blood cells. In addition, this combination offered $65 \%$ protective effects against ascariosis [31]. These effects were observed as early as in the first days of infection. The production of the various types of immunoglobulins can be affected by glucans, with lower doses favoring IgA [32]. Specific response to immunization was not clear with some reporting lowering effects of anthropic rhinitis vaccine [33] and some reporting enhanced effects of immunization with ovalbumin [24].

Additional study showed that the supplementation particularly influenced expression of lymphocyte phenotypes, lymphoid cell proliferation in response to stimulation, and ex vivo of enterotoxigenic Escherichia coli adhesion to enterocytes. The proportion of CD4 T cell subpopulations in mesenteric lymph nodes, Peyer's patches and CD8 T cells in peripheral blood was greater in pigs fed with glucan. It was concluded that a greater nutritional intake of glucan resulted in a greater increase of peripheral blood leukocytes and specifically increased the counts of naive $T$ cells. 
The immune systems of the newly-weaned pigs faced strong challenges at the time of weaning. Infections were common during this period, and dietary interventions may have influenced immune function [17]. Although some of the measurements were not influenced by increasing the glucan content of the diet, many of the intestinal and peripheral immune measures were changed, some in a dosedependent manner. However, the concurrent increase in intestinal permeability and enterocyte pathogen-binding warrants further investigation before glucans can be recommended for supplementing the diet of weanling pigs.

In our study we focused on comparison of the effects of two different types of insoluble, fungi-derived glucans as dietary supplement in piglets. Following supplementation, both glucans stimulated growth, phagocytic activity, and IL2 production. In addition, both glucans significantly lowered the cortisol and TNF- $\alpha$ levels after lipopolysaccharide challenge [34].

The mechanisms responsible for the growth improvements were not clear, as the energetic contribution of the glucans to the feed at dosages used was negligible. Plausible explanations might be stress reduction, effects on GI tract microbiota [35] on gut permeability [18] and reduction of the negative effects of LPS on feed intake. The effects of glucan after a lipopolysaccharide challenge were manifested in reduction of levels of both TNF- $\alpha$ and stress hormone cortisol, which corresponded to the results found in similar porcine models of LPS challenge after weaning [36]. In this study, supplements (glucan and vitamin C) were given in whole milk within $36 \mathrm{~h}$ of birth for two weeks; upon which the animals were challenged with an IV-applied lipopolysaccharide. Glucan supplementation increased average daily gain and increased expression of intestinal TNF- $\alpha$. In the case of glucan alone, the strong increase of lung expression of TNF- $\alpha$ was observed. The resistance of pig neutrophils to respond to glucan challenge by oxidative burst cannot be currently explained $[11,18]$ as it would be the first case of species-related resistance. However, the possibility that in vitro stimulation might not fully reflect the situation in vivo cannot be overlooked. In addition, some studies revealed that the response of porcine neutrophils to the glucan challenge depends on the type of glucan, as soluble glucans Laminarin and scleroglucan had no effects, but insoluble glucans showed significant stimulation [37]. The effects of glucan on pig immunity are summarized in Table 1.

In cattle, the effects of glucan were studied only marginally. Estrada et al. found that oat beta glucan administration had no effects in healthy beef steers, but improved the immunity in immunosuppressed animals [38]. A small scale study suggested that supplementation with glucan isolated from Aureobsidium pollulans might change the expression of cytokines in the serum and affect bacterial flora in the intestine [39]. Additional study found different effects based on type and purity of glucan used. Both glucans increased the feed uptake, but differed in modulation of immune responses [40].

\section{CONCLUSION}

Glucans are considered to be biological response modifiers exerting a variety of biological and immuno-
Table 1. Effects of glucan on pig immunity.

\begin{tabular}{|l|c|}
\hline \multicolumn{1}{|c|}{ Effects } & Reference \\
\hline \hline No effects & {$[15]$} \\
\hline Little effects on antibody production & {$[16]$} \\
\hline Improvement of hematology & {$[16]$} \\
\hline Downregulation of IL-6 and TNF- $\alpha$ & {$[24]$} \\
\hline Upregulation of IL-10 & {$[26]$} \\
\hline Decrease of Th-related cytokines & {$[29]$} \\
\hline Protection against infection & {$[30]$} \\
\hline Stimulation of phagocytosis & {$[31]$} \\
\hline Protection against ascariosis & {$[31]$} \\
\hline Increase in IgA production & {$[32]$} \\
\hline Stimulation of IL-2 and phagocytosis & {$[34]$} \\
\hline Suppression of TNF- $\alpha$ & {$[34]$} \\
\hline
\end{tabular}

pharmacological properties [41,42]. These immunomodulators have the capacity to stimulate both innate and specific immunity. The current studies suggested that glucansupplemented feed might improve both the growth and overall health of commercially farmed animals including pigs. However, we have to keep in mind that glucans are structurally relatively very variable molecules and may contain a variety of impure compounds. Preferentially, they are contaminated by cell wall proteins. It is not known to which extent the structural variation in glucan molecule, its molecular weight, and quantity of various contaminating substances modify the glucan effect in promotion of its growth performance and immune stimulation. The literature describing effects of glucans on pig immunity offers some promising studies, but is still too scarce and disparate to ascertain these effects.

Therefore, the use of beta-glucans for pig food supplementation with the aim to improve pig growth performance and immune resistance toward various bacterial, viral, and fungal illnesses of pigs requires further investigations.

\section{CONFLICT OF INTEREST}

The authors confirm that this article content has no conflict of interest.

\section{ACKNOWLEDGEMENTS}

Declared none.

\section{REFERENCES}

[1] Du Pasquier, L. The immune system of vertebrates and invertebrates. Comp. Biochem. Physiol. Part B, 2001, 129, 1-15.

[2] Casewell, M.; Friis, C.; Marco, E.; McMullin, P.; Phillips, I. The European ban on growth-promoting antibiotics and emerging consequences for human and animal health. J. Antimicrob. Chemother., 2003, 52, 159-161. 
[3] Suzuki, I.; Tanaka, H.; Kinoshita, A.; Oikawa, S.; Osawa, M.; Yadomae, T. Effect of orally administered beta-glucan on macrophage function in mice. Int. J. Immunopharmacol., 1990, 12, 675-84.

[4] Chen, D.; Ainsworth, A. J. Glucan administration potentiates immune defense mechanism of chanel catfisch Ictalurus punctatus Rafinesque. J. Fish Dis., 1992, 15, 295-304.

[5] Jeney, G.; Anderson, D. P. Glucan injection or bath exposure given alone or in combination with a bacterin enhance the non-specific defence mechanism in rainbow trout (Oncorhyncus mykiss). Aquaculture, 1993, 116, 315-329.

[6] Jørgensen, J. B.; Robertsen, B. Yeast $\beta$-glucan stimulates respiratory burst activity in Atlantic salmon (Salmo salar L.) macrophages. Dev. Comp. Immunol., 1995, 19, 43-57.

[7] Selvaraj, V.; Sampath, K.; Sekar, V. Use of glucan from Saccharomyces cerevisiae as an immunostimulant in carp: impact on hematology, phagocyte function, and infection with Aeromonas hydrophila. Isr J. Aquacult Bamidgeh, 2005, 57, 39-48.

[8] Sealey, W. M.; Barrows, F. T.; Hang, A.; Johansen, K. A.; Overturf, K.; LaPatra, S. E.; Hardy, R. W. Evaluation of the ability of barley genotypes containing different amounts of $\beta$-glucan to alter growth and disease resistance of rainbow trout Oncorhynchus mykiss. Anim. Feed Sci. Technol., 2008, 141, 115-128.

[9] Jørgensen, J. B.; Sharp, G. J. E.; Secombes, C. J.; Robertson, B. Effects of yeast cell wall glucan on the bactericidal activity of rainbow trout macrophages. Fish Shellfish Immunol., 1993, 3, 5158.

[10] Vetvicka, V.; Vannucci, L.; Sima, P. The effects of $\beta$ - glucan on fish immunity. N. Am. J. Med. Sci., 2013, 5, 580-588.

[11] Dritz, S. S.; Shi; J.; Kielian, T. L.; Goodband, R. D.; Nelssen, J. L.; Tokach, M. D.; Chengappa, M. M.; Smith, J. E.; Blecha, F. Influence of dietary beta-glucan on growth performance, nonspecific immunity, and resistance to Streptococcus suis infection in weanling pigs. J. Anim. Sci., 1995, 73, 3341-3350.

[12] Wierup, M. The Swedish experience of the 1986 year ban of antimicrobial growth promoters, with special reference to animal health, disease prevention, productivity, and usage of antimicrobials. Microbial Drug Res., 2001, 7, 183-190.

[13] Fortin, A.; Robertson, W. M.; Kibite, S.; Landry, S. J. Growth performance, carcass and pork quality of finisher pigs fed oat-based diets containing different levels of beta-glucans. J. Anim. Sci., 2003, 81, 449-456.

[14] van Nevel, C. J.; Decuypere, J. A.; Dierick, N.; Molly, K. The influence of Lentinus edodes (Shiitake mushroom) preparations on bacteriological and morphological aspects of the small intestine in piglets. Arch. Tierernahr., 2003, 57, 399-412.

[15] Hiss, S.; Sauerwein, H. Influence of dietary ss-glucan on growth performance, lymphocyte proliferation, specific immune response and haptoglobin plasma concentrations in pigs. J. Anim. Physiol. Anim. Nutr. (Berl.), 2003, 87, 2-11.

[16] Amornlertviman, S.; Kidrob, R.; Sangngam, S.; Chavananiku, Y.; Nuntaprasert, A. Effects of Saccharomyces cerevisiae's cell wall IImmuno-Aid) on growth performance, haptoglobin and immunity in weaning pigs. Proc. $7^{\text {th }}$ Chula Univ. Vet. Sci. Ann. Con., 2008, p.79

[17] Johnson, I. R.; Ball, R. O.; Baracos, V. E.; Field, C. J. Glutamine supplementation influences immune development in the newly weaned piglet. Dev. Comp. Immunol., 2006, 30, 1191-1202.

[18] Ewaschuk, J. B.; Johnson, I. R.; Madsen, K. L.; Vasanthan, T.; Ball, R.; Field, C. J. Barley-derived $\beta$-glucans increases gut permeability, ex vivo epithelial cell binding to $E$. coli, and naive Tcell proportions in weanling pigs. Anim. Sci., 2012, 90, 2652-2662.

[19] Virshchevskaya, E. V.; Alekseeva, L. G.; Reshetov, P. D.; Phomicheva, N. N.; Parphenyuk, S. A.; Ilyina, A. V.; Zueva, V. S.; Lopatin, S. A.; Levov, A. N.;Varlamov, V. P. Mucoadjuvant properties of lipo- and glycoconjugated derivatives of oligochitosans. Eur. J. Med. Chem., 2009, 44, 2030-2037.

[20] Mineo, H.; Amano, M.; Chiji, H.; Shigematsu, N.; Tomita, F.; Hara, H. Indigestible disaccharides open tight junctions and enhance net calcium, magnesium, and zinc absorption in isolated rat small and large intestinal epithelium. Dig. Dis, Sci., 2004, 49, $122-132$.

[21] Stuyven, E.; Van den Broeck, W.; Nauwynck, H.; Goddeeris, B. M.; Cox, E. Oral administration of beta-1,3/1,6-glucan Macrogard fails to enhance the mucosal immune response following oral F4 fimbrial immunisation in gnotobiotic pigs. Vet. Immunol. Immunopathol., 2010, 137, 291-297.

[22] Samuel, B. S.; Gordon, J. I. A humanized gnotobiotic mouse model of host-archaeal-bacterial mutualism. Proc. Natl. Acad. Sci. U $S$ A, 2006, 103, 10011-10016.

[23] Luo, Y. H.; Li, H.; Luo, J. Q.; Zhang, K. Y. Yeast-derived $\beta$-glucan substrate significantly increased the diversity of methanogens during in vitro fermentation of porcine colonic digesta. J. Integrat. Agricult., 2013, 12, 2229-2234.

[24] Li, J.; Li, D. F.; Xing, J. J.; Cheng, Z. B.; Lai, C. H. Effects of $\beta$ glucan extracted from Saccharomyces cerevisiae on growth performance and immunological and somatotropic responses of pigs challenged with Escherichia coli lipopolysaccharide. J. Anim. Sci., 2006, 84, 2374-2381.

[25] Spurlock, M. E. Regulation of metabolism and growth during immune challenge: an overview of cytokine function. J. Anim. Sci., 1997, 75, 1773-1783.

[26] Clarke, C. J.; Hales, A.; Hunt, A.; Foxwell, B. M. IL-10-mediated suppression of TNF-alpha production is independent of its ability to inhibit NF kappa B activity. Eur. J. Immunol., 1998, 28, 17191726.

[27] Kogan, G.; Kocher, A. Role of yeast cell wall polysaccharides in pig nutrition and health protection. Livestock Sci., 2007, 109, 161165 .

[28] Hooda, S.; Matte, J. J.; Vasanthan, T.; Zijlstra, R. T. Dietary oat $\beta$ glucan reduces peak net glucose flux and insulin production and modulates plasma incretin in portal-vein catheterized grower pigs. J. Nutr., 2010, 140, 1564-1569.

[29] Ryan, M. T.; O'Shea, C. J.; Collins, C. B.; O'Doherty, J. V.; Sweeney, T. Effects of dietary supplementation with Laminaria hyperborea, Laminaria digitata, and Saccharomyces cerevisiae on the IL-17 pathway in the porcine colon. J. Anim. Sci., 2012, 90, 263-265.

[30] Stuyven, E.; Cox, W.; Vancaeneghem, S.; Arnouts, S.; Deprez, P.; Goddeeris, B. M. Effects of $\beta$-glucans on an ETEC infection in piglets. Vet. Immunol. Immunopathol., 2009, 128, 60-66.

[31] Benova, M.; Boroskova, Z.; Soltys, J.; Dubaj, J.; Szechenyi, S. Effect of glucan preparation on immunocompetent cells and phagocytic ability of blood leucocytes in experimental ascariosis of pigs. Vet. Parasitol., 1992, 41, 157-166.

[32] Sauerwein, H.; Schmidz, S.; Hiss, S. Effects of a diatary application of a yeast cell wall extract on innate and acquired immunity, on oxidative status and growth performance on weanling piglets and on the ileal epithelium in fattened pigs. J. Anim. Physiol. Anim. Nutr. (Berl.), 2007, 91, 369-380.

[33] Hahn, T. W.; Lohakare, J. D.; Lee, S. L.; Moon, W. K.; Chae, B. J. Effects of supplementation of $\beta$-glucans on growth performance, nutrient digestibility, and immunity in weanling pigs. J. Anim. Sci., 2006, $84,1422-1428$.

[34] Vetvicka, V.; Oliveira, C. $\beta(1-3)(1-6)$-D-glucans modulate immune status in pigs: potential importance for efficiency of commercial farming. Ann. Transl. Med., 2, 2014, doi:10.3928/j.issn.23055839.2014.01.04

[35] Murphy, P.; Dal Bello, F.; O'Doherty, J. V.; Arendt, E. K. Sweeney, T. Coffey, A. Effects of cereal $\beta$-glucans and enzyme inclusion on the porcine gastrointestinal tract microbiota. Anaerobe, 2012, 18, 557-565.

[36] Eicher, S. D.; McKee, C. A.; Carroll, J. A.; Pajor, E. A. Supplemental vitamin $\mathrm{C}$ and yeast cell wall beta-glucan as growth enhancers in newborn pigs and as immunomodulators after an endotoxin challenge after weaning. J. Anim. Sci., 2006, 84, 2352 2360.

[37] Sonck, E.; Stuyven, E.; Goddeeris, B.; Cox, E. The effect of $\beta$ glucans on porcine leukocytes. Vet. Immunol. Immunopathol., 2010, 135, 199-207.

[38] Eicher, S. D.; Wesley, I. V.; Sharma, V. K.; Johnson, T. R. Yeast cell-wall products containing beta-glucan plus ascorbic acid affect neonatal Bos taurus calf leukocytes and growth after a transport stressor. J. Anim. Sci., 2010, 88, 1195-1203.

[39] Estrada, A.; van Kessel, A.; Laarveld, B. Effect of administration of oat beta-glucan on immune parameters of healthy and immunosuppressed beef steers. Can. J. Vet. Res., 1999, 63, 261268.

[40] Uchiyama, H.; Uwai, A.; Asada, Y.; Muramatsu, D.; Aoki, S.; Kawata, K.; Kusano, K.; Nagashima, K.; Yasokawa, D.; Okabe, M.; Miyazaki, T. A small scale study on the effects of oral 
administration of the $\beta$-glucan produced by Aureobasidium pullulans on milk quality and cytokine expression of Holstein cows, and on bacterial flora in the intestines of Japanese black calves. BMC Res. Notes, 2012, 5, doi:10.1186/1756-0500-5-189.
[41] Miura, N. N.; Ohno, N.; Aketagawa, J.; Tamura, H.; Tanaka, S.; Yadomae, T. Blood clearance of (1-->3)-beta-D-glucan in MRL lpr/lpr mice. FEMS Immunol. Med, Microbiol., 1996, 13, 51-57.

[42] Vetvicka, V. $\beta$-Glucans as Natural Biological Response Modifiers. Nova Biomedical: New York, 2013.

Received: August 29, 2014

Revised: September 20, 2014

Accepted: October 01, 2014

(C) Vetvicka et al.; Licensee Bentham Open.

This is an open access article licensed under the terms of the Creative Commons Attribution Non-Commercial License (http://creativecommons.org/licenses/ by-nc/3.0/) which permits unrestricted, non-commercial use, distribution and reproduction in any medium, provided the work is properly cited. 